\title{
44530 - PARA-VERTEBRAL BLOCK VERSUS EPIDURAL ANESTHESIA IN ULTRA FAST TRACK CARDIAC SURGERY
}

\author{
Jean-François Olivier, Montreal General Hospital, Montreal, QC, Canada; \\ David Bracco, Montreal General Hospital; \\ Nicolas Noiseux, Hotel Dieu de Montreal; \\ Ignacio Prieto, Hotel Dieu de Montreal; \\ Fadi Basile, Hotel Dieu de Montreal; \\ T M Hemmerling, Montreal General Hospital;
}

\begin{abstract}
INTRODUCTION:
Epidural anesthesia provides superior analgesia, better respiratory outcome and myocardial protection after cardiac surgery $(1,2)$ but is at risk of epidural hematoma. Paravertebral block related hematoma may have less consequences and anesthesiologists may feel more comfortable with this technique. The aim of this study is to compare the analgesia provided by high thoracic epidural analgesia (Epidural group) versus single-shot para-vertebral blocks (PVB group) after cardiac surgery using an ultra-fast track strategy.
\end{abstract}

\section{METHODS:}

Local IRB approval was obtained for this study. 52 patients undergoing cardiac surgery were enrolled in this observational study: 26 received a T3-T4 epidural and 26 received bilateral T1 to T7 paravertebral blocks prior to induction. Epidural analgesia was achieved using bupivacaine $0.1 \%$ at $8-10 \mathrm{ml}$ per hour up to $48 \mathrm{~h}$ po, paravertebral blocks were performed in a single-shot loss resistance technique using $3 \mathrm{ml}$ of bupivacaine $0.25 \%$ each. Anesthesia was maintained with fentanyl $<5$ microgram per $\mathrm{kg}$ and sevoflurane titrated to a BIS of 40-50. Po. analgesia was provided by the epidural catheter or by PCA-morphine in the PVB group. Postoperative analgesia was assessed by the VAS and patients were followed-up until discharge.

\section{RESULTS:}

Patient groups were not significantly different in terms of preoperative risk factors, ejection fraction or type of surgery. All cases were successfully extubated in the operating room within 15 min. CABG patients received a mean of 2.9 grafts, with a cumulative ischemia time of 10 minutes for OP-CABG. The mean surgical duration was $121^{\prime}$. Pain scores were consistently lower in the epidural group versus the PV group. 


\section{Visual analogic score}

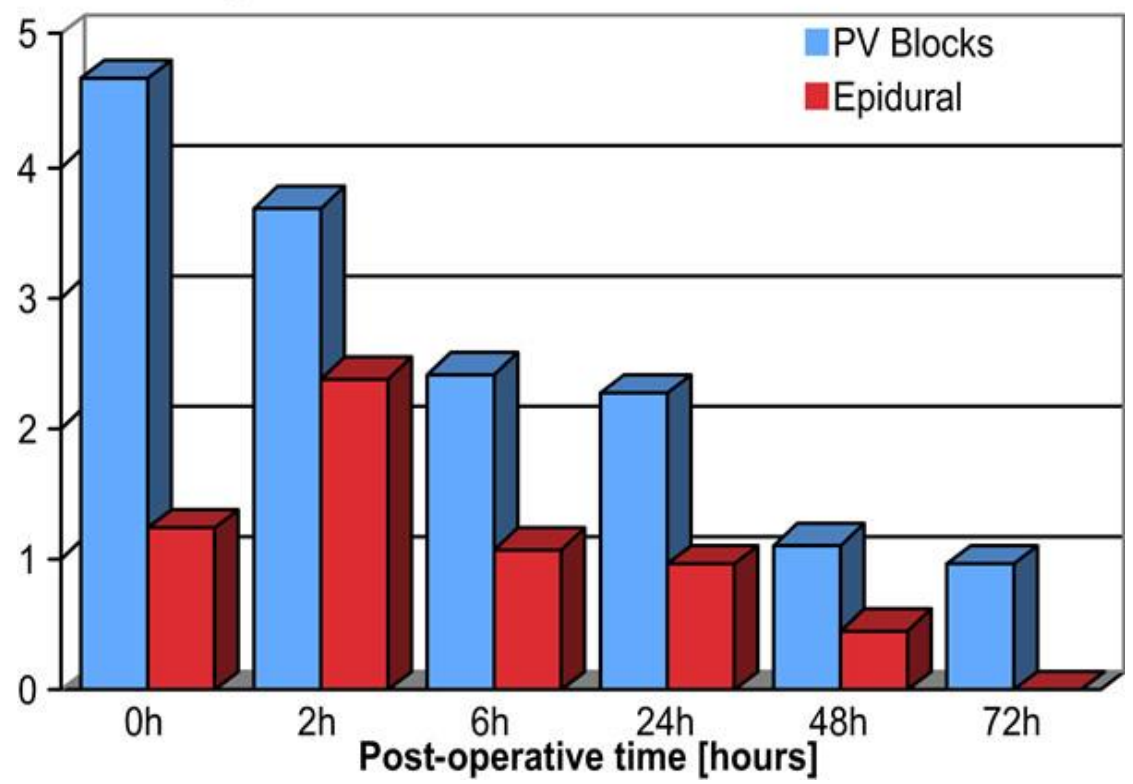

PVB patients had the first pain 45 minutes after surgery, received $6 \mathrm{mg}$ loading dose and $43 \mathrm{mg}$ morphine during the first 24 hours and $70 \mathrm{mg}$ for the first 48 hours. Median PV block duration was 245 minutes. Patients with an epidural received no opioids during the postoperative course. There was no neurological complication with either technique.

\section{CONCLUSION}

Epidural is superior to paravertebral blocks after cardiac surgery and allows an opioid free postoperative course.

\section{References}

$1 \quad$ Anesth Analg. 2006; 102: 45-64

2 Semin Cardiothorac Vasc Anesth. 2005; 9: 87-104 